\section{Manned spacecraft progress}

EUROPEAN plans to build manned spacecraft advanced a little further at last week's meeting of the European Space Agency (ESA) in Paris, with the British scheme for a vehicle called HOTOL gaining a little on its French rival Hermes. West Germany's newer project, called "Sänger", which closely resembles HOTOL, also made a little progress.

In the corridors last week, there was talk that Hermes might be set back by pressure to provide this mini-shuttle with some form of escape system to guard against a disaster of the kind that overtook the US Challenger last January. The snag is that Hermes is planned to be only half the size of the US shuttle, so that the addition of escape systems may not be feasible. One possibility would be to restrict flights to military personnel, where the risk of the loss of life would be more easily justified. Even so, and in spite of doubts of the wisdom of spending so much on manned spaceflight, ESA agreed to a six-month technical study of the Hermes proposal.

The agency also agreed to support a three-year study of HOTOL and Sänger. Both projects involve horizontal takeoff. The West German project would lift a rocket-engined vehicle piggy-back through the lower atmosphere by means of a Mach-6 aircraft. The British project, technically more ambitious, would use a still-secret Rolls-Royce engine concept able to switch from an air-breathing to a rocket mode. Both projects are claimed to be capable of reducing launching costs to a fifth.

ESA's decision to study the two projects is a victory for British Aerospace, HOTOL's designer, which has championed the cause for the past two years. It also marks European concern that the United States and Japan will corner the world launch market in coming decades.

Hermes and the two horizontal launching vehicles are not technically competitive; Hermes is hardly more than an unpowered reentry vehicle whose success would depend on the development of later versions of the Ariane launcher. But there will be competition between the projects for funds, with Hermes priced (by France) at about $£ 2,000$ million to 1995 and HOTOL-like vehicles costing about the same but spread over two decades

Hard choices are being put off until a ministerial meeting of ESA planned for the middle of next year, but last week's agreement to launch a "preparatory study" of Hermes, to be carried out at the Toulouse headquarters of the French national space agency, should show the way the wind is blowing. One sign will be the extent to which ESA members commit themselves to the cost of the planning 30 November.

\section{European research}

phase, estimated at 48 million ECU (£35 million). British officials were talking last week of the possibility of a 10 per cent contribution (twice the British stake in Ariane). A previously divided West German government has also indicated serious interest, although the final figures will not be known until the closing date on

In Britain, the timescale is probably even shorter. The newly formed National Space Centre put a comprehensive plan for British research and development to

\title{
Prospect of an empty barrel
}

EUROPEAN research ministers failed to agree last week whether to double the European Commission's research budget for 1987-91 - or to reduce it. The differences among ministers at an 'informal' lunch in Luxembourg were so great, indeed, that some in the Commission fear there will be no framework for research next year. Stop-gap proposals have been prepared for four individual programmes due to run out of cash in December (in telecommunications, health, aid to developing countries and aids to innovation in Europe).

Mr Geoffrey Pattie, Britain's technology minister, who is now president of the council of research ministers, is organizing a series of meetings in an attempt to reach a compromise before 9 December, the date of the last research ministers' meeting of the year and the last of his presidency.

The gap Pattie has to bridge is vast, that between the $£ 2,500$ million or so that Britain, France and West Germany believe would be in their interests and the $£ 6,200$ million proposed by the Commission and backed by most other states. Commission sources estimate a figure of around $£ 4,200$ million would be needed to maintain present support. Earlier this year it had been planning on a figure at least double this. It is clear that the figures now being discussed represent a major blow to Brussels' ambitions.

Brussels research commissioner KarlHeinz Narjes is nevertheless said to be optimistic. He believes Pattie is under pressure to reach an agreement by $\mathrm{De}$ cember, and is also encouraged by the majorities by which most of the individual Commission proposals are accepted.

But majorities are not enough. Although most individual research proposals by the Commission are approved by a majority of governments, none may be agreed on this occasion because the Commission has followed the letter of the law and demanded unanimous agreement of the government early in the summer. The government's response is expected in midNovember, before a final decision on Hermes must be made.

One question to be resolved is that present British spending on space, roughly $£ 100$ million a year, may have to be increased by roughly $£ 50$ million a year if the next ministerial meeting of ESA agrees to a 70 per cent increase of the agency's budget to cover, among other things, the cost of the production phase of Ariane 5 . Full 10 per cent participation in the construction of Hermes, whose estimated cost some think could be a factor of five too small, would add another $£ 20$ million to the bill.

Robert Walgate

its package before discussing details. Although it is now technically possible for the Commission to sponsor programmes in which only some members participate, and even to allow outside participants, the Commission has in fact proposed no clear mechanism by which such programmes will be funded and agreed.

In fear that the framework will not be agreed, therefore, the Commission has proposed extensions to its RACE (Research and Development in Advanced Communications Technologies in Europe), medical health (largely AIDS and cancer), science and technology for development and SPRINT (Strategic Programme for Innovation and Technology Transfer) projects, all of which run out of cash in January. Of these, RACE is by far the biggest ( $£ 560$ million over five years,): it aims at developing European standards and common technologies in integrated broad-band communication networks. West Germany is firmly against RACE, however, being unwilling to open up its national telecommunications markets, and believing that its major electronics company Siemens can manage without outside collaboration. The medical health programme, it is claimed in Brussels, would link one in four of Europe's medical research groups in joint projects for a cost of $£ 26$ million over three years. In research for poor countries, a four-year $£ 56$ million programme would concentrate on improving the indigenous research capabilities in wide areas of agricultural and health research. SPRINT ( $£ 7$ million over two years) would continue, among other things, the development of a network of management and technology consultants specialized in dealing with small and medium-sized companies, to help the innovation process cross national boundaries in Europe. Without funding in December, all these programmes will come to an end, the Commission says.

Robert Walgate 